\title{
$\mathrm{C}, \mathrm{Cl}$ and $\mathrm{H}$ compound-specific isotope analysis
}

\author{
to assess natural versus $\mathrm{Fe}(0)$ barrier-induced
}

degradation of chlorinated ethenes at a

\section{contaminated site}

Carme Audí-Miró $^{\dagger^{*}}$, Stefan Cretnik ${ }^{\ddagger}$, Clara Torrentó ${ }^{\dagger}$, Mònica Rosell ${ }^{\dagger}$, Orfan Shouakar-Stash ${ }^{\S}$, Neus Otero $^{\dagger}$, Jordi Palau ${ }^{\phi}$, Martin Elsner ${ }^{\sharp}$, Albert Soler ${ }^{\dagger}$

${ }^{\dagger}$ Grup de Mineralogia Aplicada i Medi Ambient. Departament de Cristal-lografia, Mineralogia i Dipòsits Minerals, Facultat de Geologia, Universitat de Barcelona (UB), Martí Franquès s/n, 08028. Barcelona, Spain

${ }^{\star}$ Institute of Groundwater Ecology, Helmholtz Zentrum München-National Research Center for Environmental Health, Ingolstädter Landstrasse 1, D-85764 Neuherberg, Germany

${ }^{\S}$ Department of Earth \& Environmental Sciences, 200 University Ave. W, N2L 3G1 Waterloo, Ontario, Canada

${ }^{\Phi}$ Université de Neuchâtel. CHYN - Centre d'Hydrogéologie. Rue Emile-Argand 11, CH - 2000, Neuchâtel, Switzerland 


\section{Corresponding Author.}

*Carme Audí-Miró. Phone: +34 934021343; Fax: +34 934021340, e-mail: carmeaudi@ub.edu

\section{ABSTRACT}

Compound-specific isotopic analysis of multiple elements $(\mathrm{C}, \mathrm{Cl}, \mathrm{H})$ was tested to better assess the effect of a zero-valent iron-permeable reactive barrier (ZVI-PRB) installation at a site contaminated with tetrachloroethene (PCE) and trichloroethene (TCE). The focus was on 1) using ${ }^{13} \mathrm{C}$ to evaluate natural chlorinated ethene biodegradation and the ZVI-PRB efficiency; 2) using dual element ${ }^{13} \mathrm{C}$ ${ }^{37} \mathrm{Cl}$ isotopic analysis to distinguish biotic from abiotic degradation of cis-dichloroethene (cis-DCE); and 3) using ${ }^{13} \mathrm{C}_{-}{ }^{37} \mathrm{Cl}-{ }^{2} \mathrm{H}$ isotopic analysis of cis-DCE and TCE to elucidate different contaminant sources. Both biodegradation and degradation by ZVI-PRB were indicated by the metabolites that were detected and the ${ }^{13} \mathrm{C}$ data, with a quantitative estimate of the ZVI-PRB efficiency of less than $10 \%$ for PCE. Dual element ${ }^{13} \mathrm{C}-{ }^{37} \mathrm{Cl}$ isotopic plots confirmed that biodegradation was the main process at the site including the ZVI-PRB area. Based on the carbon isotope data, approximately $45 \%$ and $71 \%$ of PCE and TCE, respectively, were estimated to be removed by biodegradation. ${ }^{2} \mathrm{H}$ combined with ${ }^{13} \mathrm{C}$ and ${ }^{37} \mathrm{Cl}$ seems to have identified two discrete sources contributing to the contaminant plume, indicating the potential of $\delta^{2} \mathrm{H}$ to discriminate whether a compound is of industrial origin, or whether a compound is formed as a daughter product during degradation.

Keywords: chlorinated ethenes, stable isotopes, zero-valent iron 


\section{INTRODUCTION}

Tetrachloroethene (PCE) and trichloroethene (TCE) are dense chlorinated aliphatic hydrocarbons (CAHs) that have been used on a large scale as metal and textile cleaners and degreasers. In the aquifer, because these compounds are denser than water, they migrate downwards through the saturated zone until they reach a confining layer, forming pools and constituting a long term source of groundwater contamination. PCE and TCE are among the most frequently detected volatile organic compounds (VOCs) in urban area wells ${ }^{[1]}$.

Under reducing conditions, PCE and TCE can experience sequential microbial dechlorination to cis-DCE, VC and nontoxic ethene and ethane. Frequently, however, incomplete reductive dechlorination with the accumulation of cis-DCE and VC can occur due to the lack of specialized degrader communities ${ }^{[2]}$. The accumulation of these compounds is of great concern because of their potential carcinogenicity ${ }^{[3]}$, with $\mathrm{VC}$ as the most toxic product of the degradation chain.

Zero-valent iron permeable reactive barrier (ZVI-PRB) treatment involves the placement of particulate cast ZVI in the flow path of a contaminated plume. As the plume moves through the barrier, ZVI is designed to sequentially degrade PCE by reductive dechlorination to form the nontoxic compounds ethene and ethane ${ }^{[4]}$. In contrast to biodegradation, which tends to occur predominantly by hydrogenolysis, ZVI is able to degrade the chlorinated compounds preferentially through the $\beta$-dichloroelimination pathway ${ }^{[5,6,7]}$. This pathway can circumvent the production of VC, producing acetylene, longer chain hydrocarbons (C3 to C6), ethene and ethane ${ }^{[5]}$.

Compound Specific Isotope Analysis (CSIA) bears the potential to discriminate the dominant degradation mechanisms and to estimate the extent of degradation. To use the isotopic approach in field applications, it is necessary to determine the isotopic enrichment factor $\varepsilon$ of a particular degradation mechanism. Numerous studies reported isotopic enrichment factors for carbon $\varepsilon_{\mathrm{C}}$ of chlorinated ethenes from biodegradation experiments with mixed cultures (ranging from -2.7 to -7.1 $\%$ for PCE, from -2.5 to $-16.0 \%$ for TCE and from -14.1 to $-29.7 \%$ for cis-DCE) ${ }^{[9-14]}$ and for 
abiotic ZVI degradation (-5.7\% to $-25.3 \%$ or PCE, $-7.5 \%$ o to $-26.5 \%$ or for TCE, $-6.9 \%$ o to $-21.7 \%$ o for $c i s$-DCE and from $-6.9 \%$ to $-19.4 \%$ or $\mathrm{VC})^{[6,7,14-16]}$. Because the ranges of $\varepsilon_{\mathrm{C}}$ for the two types of degradation overlap, it is not possible to discriminate between biodegradation and abiotic ZVI degradation through the determination of the respective $\mathrm{C}$ isotope effects alone. The combination of C isotope effects with other elements, however, has the potential to obtain precisely such discrimination and to distinguish between the different transformation pathways ${ }^{[17-19]}$. The recent improvement of analytical methods for measuring chlorine isotope ratios for chlorinated ethenes enabled the application of the dual ${ }^{13} \mathrm{C}-{ }^{37} \mathrm{Cl}$ approach in field studies ${ }^{[20]}$. Our previous laboratory studies for TCE degradation with ZVI ${ }^{[7]}$ reported a dual isotope slope $\left(\varepsilon_{\mathrm{C}} / \varepsilon_{\mathrm{Cl}}\right.$, i.e., the ratio between $\mathrm{C}$ and $\mathrm{Cl}$ fractionations) of 5.2. This value is close to the value obtained by Lojkasek-Lima et al. ${ }^{[21]}$ for TCE abiotic degradation with ZVI $(4.2 \%$ ) in a mixture with PCE and cis-DCE. But, while 5.2 $\% \circ$ is distinguishable from the value reported by Wiegert et al. ${ }^{[22]}\left(\varepsilon_{\mathrm{C}} / \varepsilon_{\mathrm{Cl}}\right.$ of 2.7$)$ for a microbial culture enriched in Desulfitobacteria and by Cretnik et al. ${ }^{[23]}\left(\varepsilon_{\mathrm{C}} / \varepsilon_{\mathrm{Cl}}\right.$ between 3.4 and 3.8) for Geobacter lovleyi and Desulfitobacterium hafniense, this value overlaps significantly with values reported by Kuder et al. ${ }^{[24]}$ for a Bio-Dechlor Inoculum (BDI) culture enriched in Dehalococcoides sp. $\left(\varepsilon_{\mathrm{C}} / \varepsilon_{\mathrm{Cl}}: 4.7\right)$. Available data suggest that a better distinction may be possible for $c i s$-DCE. Abe et al. ${ }^{[19]}$ reported slopes $\left(\varepsilon_{\mathrm{C}} / \varepsilon_{\mathrm{Cl}}\right)$ for reductive dechlorination by a mixed culture enriched with Dehalococcoides ethenogenes for cis-DCE of 12.5. This value clearly falls in a different range

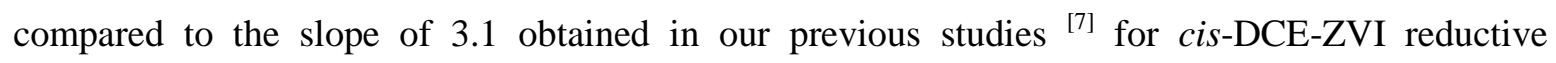
dechlorination. However because cis-DCE is also a product in the TCE dechlorination sequence, there is a more complex picture to resolve.

To try to distinguish different origins of cis-DCE (daughter of a TCE that is a metabolite from PCE versus daughter of a TCE that is an original industrial product), this study for the first time employs compound-specific hydrogen isotope analysis on field samples. Earlier studies have already proposed $\delta^{2} \mathrm{H}$ as a useful tool to distinguish the origin of TCE, reporting that manufactured TCE 
presented very positive $\delta^{2} \mathrm{H}$ values (between +400 to $+600 \%$ o), ${ }^{[25,26]}$ in contrast with the TCE produced from PCE reductive dechlorination, with more negative $\delta^{2} \mathrm{H}$ values $\left(-350 \%\right.$ ) ${ }^{[25]}$.

Therefore, the main goal of this work was to test the compound-specific isotopic analysis of

multiple elements $(\mathrm{C}, \mathrm{Cl}, \mathrm{H})$ to assess a ZVI-PRB treatment through different ways: 1$)$ by using ${ }^{13} \mathrm{C}$ analysis to evaluate the occurrence of natural chlorinated ethene biodegradation at the site where the ZVI-PRB treatment is applied, to obtain the $\varepsilon_{\mathrm{C}}$ of the biodegradation from microcosm experiments, and to quantify the ZVI-PRB treatment efficiency; 2) by using the dual element ${ }^{13} \mathrm{C}-{ }^{37} \mathrm{Cl}$ isotopic approach to discriminate whether cis-DCE is being degraded abiotically due to the ZVI-PRB effect or biotically due to natural degradation; 3 ) according to results of point 2 , to choose the appropriate $\varepsilon_{\mathrm{C}}$ (the biotic or the abiotic) to quantify the real degradation at the field site; and 4) by using triple element ${ }^{13} \mathrm{C}_{-}{ }^{37} \mathrm{Cl}-{ }^{2} \mathrm{H}$ isotopic analysis of $c i s$-DCE and TCE, to elucidate different contaminant sources to see the potential of the $\delta^{2} \mathrm{H}$ approach to distinguish TCE of industrial origin.

\section{SITE DESCRIPTION}

The study site is located in the industrial area of Granollers, $20 \mathrm{~km} \mathrm{NW}$ from Barcelona, Catalonia. An automotive industry that used PCE and TCE as degreasers operated in the area from 1965 to 1989. The site is bounded on its west side by the Can Ninou creek, which continues to the S-SW (Figure 1). The water table of the aquifer is located at an average depth of $5.4 \pm 2.1 \mathrm{~m}$. Further details are provided in the Supplementary Data (SD).

The PCE and TCE contaminant plume was formed by a discharge of industrial waste water into a seepage pit located at the south of the plant (close to MW17, Fig. 1); this point is considered the contamination source area, where historical data from 2004 revealed concentrations of cis-DCE up to $160 \mathrm{mg} / \mathrm{L}$ and of its precursors PCE and TCE of 25 and $180 \mathrm{mg} / \mathrm{L}$, respectively. Before starting the present work, a dual remediation strategy was performed at the studied site: the removal of the 
contaminated soil from the source area in 2009 and the installation of a ZVI-PRB to treat the groundwater contaminant plume in 2010. The PRB was built approximately $320 \mathrm{~m}$ downstream from the contaminated source, transverse to the creek (Fig. 1). The top of the PRB was placed 4-5 $\mathrm{m}$ below the ground surface, and its size is $20 \mathrm{~m}$ long, $5 \mathrm{~m}$ high and $60 \mathrm{~cm}$ thick, with a $3 \%(\mathrm{v} / \mathrm{v})$ of granular cast ZVI in a sand matrix.

\section{METHODOLOGY}

From April 2011 to March 2013, four sampling surveys were carried out (April 2011, June 2012, October 2012 and March 2013) from both conventional and multilevel wells (see SD for details). In all surveys, concentration and $\delta^{13} \mathrm{C}$ of chlorinated ethenes were measured, whereas in the Oct-2012 survey, $\delta^{37} \mathrm{Cl}$ of PCE and cis-DCE and $\delta^{2} \mathrm{H}$ of cis-DCE and TCE were also determined $\left(\delta^{37} \mathrm{Cl}\right.$ of TCE and VC and $\delta^{2} \mathrm{H}$ of VC were not measured due to concentrations below the detection limit).

Redox-sensitive species were analyzed by standard analytical techniques as in Torrentó et al. ${ }^{[27]}$ Concentrations of chlorinated ethenes were determined by headspace analysis using a FOCUS Gas Chromatograph coupled with a DSQ II mass spectrometer (GC/MS) (Thermo Fisher Scientific, Inc., Waltham, Massachusetts, USA). Carbon isotope composition of PCE, TCE, cis-DCE and VC was analyzed using a gas chromatography-combustion-isotope ratio mass spectrometry system (GC/CIRMS) consisting of a Trace GC Ultra equipped with a split/splitless injector, coupled to a Delta V Advantage IRMS (Thermo Scientific GmbH, Bremen, Germany) through a combustion interface. Chlorine isotopic measurements of PCE and cis-DCE were conducted on a GC-IRMS system (Thermo Scientific, Waltham, Massachusetts, USA) consisting of a Trace GC connected to a MAT 253 IRMS with dual inlet system via a heated transfer line ${ }^{[25]}$. Hydrogen isotopic analyses of TCE and $c$ is-DCE were determined following the method developed by Shouakar-Stash and Drimmie ${ }^{[28]}$ using a Deltaplus XL CF-IRMS (Thermo Scientific GmbH, Bremen, Germany) coupled with an 
Agilent 6890 GC (Agilent Technologies, Inc., Santa Clara, California, USA) and a chromium reduction $(\mathrm{R})$ system.

Ethene, ethane and acetylene concentrations were measured using a Varian 3400 GC (Scientific Equipment Source, Oshawa, Ontario, Canada) coupled to a flame ionization detector (FID). Carbon isotope measurement of ethene was accomplished by using a purge and trap Teledyne-Tekmar XPT concentrator (Teledyne-Tekmar, Mason, Ohio, USA) coupled to a Varian 3400 GC (Agilent Technologies, Inc., Santa Clara, California, USA) and a Finnigan MAT 252 IRMS (Thermo Scientific GmbH, Bremen, Germany) via a combustion interface. Continuous flow $\delta^{2} \mathrm{H}$ analysis of ethene was conducted using the same purge and trap (Teledyne-Tekmar XPT concentrator) coupled to an HP 6890 GC system online with a micropyrolysis oven and a Finningan MAT (Thermo Scientific GmbH, Bremen, Germany) Delta Plus XL IRMS (GC/TC-IRMS). Additional details of all methodologies are provided in the SD.

\section{RESULTS AND DISCUSSION}

\subsection{Evidence of biodegradation and ZVI-PRB-mediated degradation}

From a geochemical perspective, the redox conditions of the site were conducive to biotic reductive dechlorination of chlorinated ethenes. Specifically: 1) reducing conditions prevailed in many wells (dissolved oxygen (DO) below $0.5 \mathrm{mg} / \mathrm{L}$ ) during the campaign of June-2012 (see Table S1); 2) dissolved Mn was present in concentrations up to $1.36 \mathrm{mg} / \mathrm{L}$ and dissolved $\mathrm{Fe}$ in concentrations up to $1.57 \mathrm{mg} / \mathrm{L}$; 3) nitrate concentration decreased from an average of $63 \mathrm{mg} / \mathrm{L}$ to below detection limit $(<0.1 \mathrm{mg} / \mathrm{L})$ in samples where the highest $\mathrm{Mn}$ concentrations were detected; 4) sulfate concentrations decreased in the MW17 well (from an average of $90 \mathrm{mg} / \mathrm{L}$ to $16.8 \mathrm{mg} / \mathrm{L}$ ) (Table S2). These redox conditions are also characteristic of abiotic chlorinated ethene reductive dechlorination by ZVI, which would favor this process in the ZVI-PRB area. Nevertheless, the pH analyzed 
downgradient from the barrier (approximately 7) did not correspond to the common increase in $\mathrm{pH}$ (up to $\mathrm{pH}$ of 8 - 10) that usually occurs after the corrosion of iron in water ${ }^{[29]}$.

Dechlorination products identified upgradient from the ZVI-PRB indicated that biodegradation occurred at the site. The main compounds detected were PCE, TCE (mainly in OMW6B and OMW7) and cis-DCE (Table 1). The presence of cis-DCE gave evidence of the reductive dechlorination of TCE. TCE, at the same time, could derive from PCE degradation and/or be one of the original commercial products. VC was also detected (in MW17, OMW5 and Pz3), confirming that cis-DCE was further degraded. The detection of ethene and ethane in MW17 (Table S3) indicated ongoing complete dechlorination of the chlorinated ethenes at the source area. The two most contaminated wells were OMW7 with $22 \mathrm{mg} / \mathrm{L}$ of $c i s-\mathrm{DCE}$ and $139 \mathrm{mg} / \mathrm{L}$ of TCE and MW17 with $16 \mathrm{mg} / \mathrm{L}$ of $c i s-\mathrm{DCE}$. At the rest of the wells, concentrations of all target compounds were on the order of tens to hundreds of $\mu \mathrm{g} / \mathrm{L}$ (Table 1).

Carbon isotope shifts confirmed the occurrence of biodegradation at the site (Table 1 and Fig. 2). The comparison of the lowest $\delta^{13} \mathrm{C}$ of PCE and TCE values detected in the field (-21.6 and $-23.4 \%$, respectively) (Table 1 ) to the literature $\delta^{13} \mathrm{C}$ ranges for commercial products (from -35.3 to $-23.2 \%$ o for PCE; and from -33.5 to $-25.8 \%$ for TCE) ${ }^{[25,30,31]}$, shows that both PCE and TCE might be enriched in ${ }^{13} \mathrm{C}$ and therefore had already been degraded compared to the commercial compounds originating the contamination at this site. The highest $\delta^{13} \mathrm{C}$ values of PCE, TCE and cis-DCE were detected immediately before the barrier (Table 1 and Fig. 2), indicating a higher degree of degradation at this point. In addition, PCE carbon isotope values in wells OMW5 and BR1-11 changed towards higher values during the three years of the study, indicating not only biodegradation but also an increase of the extent of the biodegradation over time (Fig. 3). The same trend was observed for cis-DCE in wells MW17 and BR1-9.5 (Fig. 3). In well MW17, $\delta^{13} \mathrm{C}$ of VC $\left(-38.4 \%\right.$ ) was depleted in ${ }^{13} \mathrm{C}$ compared to the parent compound $\left(\delta^{13} \mathrm{C}_{\mathrm{DCE}}\right.$ of $-15.7 \%$ ), as typically occurs during biodegradation (Table 1). Complementary microcosm experiments with material 
from wells Pz1 and Pz3 verified the occurrence of biodegradation upgradient from the barrier (experiments detailed in the SD).

Downgradient from the PRB, the presence of chlorinated ethenes suggested that the barrier did not achieve complete degradation of the contaminants and/or that hydraulic bypass was occurring. Lateral and underneath hydraulic bypass was suggested by the presence of PCE and cis-DCE in Pz4 and in the multilevel wells at 11 to $13 \mathrm{~m}$ depth (considering that the barrier is located at approximately $10 \mathrm{~m}$ depth). Acetylene was present only in BR4, at very low concentration, only up to $20 \mu \mathrm{g} / \mathrm{L}$ at an $8 \mathrm{~m}$ depth (Table S3), coinciding with the point located at the central part of the barrier. This would give slight evidence of abiotic degradation due to the reaction of the chlorinated ethenes through the ZVI-PRB ${ }^{[5,6,7]}$. Carbon isotope results of the multilevel wells located directly before (BR1) and directly after (BR3, BR4) the ZVI-PRB from June-2012 exhibited a small but consistent enrichment in ${ }^{13} \mathrm{C}$ in both PCE and cis-DCE from upstream to downstream of the barrier (Fig. 4A), more visible at the central part of the barrier (BR4) where the significant appearance of TCE was also observed, indicating that TCE could have been formed from PCE (from almost not detected TCE in BR1 to $46 \mu \mathrm{g} / \mathrm{L}$ in BR4-10 m, Table 1). These results suggested PCE and cis-DCE degradation by the ZVI-PRB in the NW side of the barrier, whereas no evidence of degradation was observed in the SE part of the barrier. The extent of degradation can be estimated for the parent compound, PCE, according to Equation 3 from the SD. $\delta^{13} \mathrm{C}_{0}$ and $\delta^{13} \mathrm{C}_{\mathrm{t}}$ were taken as the average earlier $\delta^{13} \mathrm{C}$ values before (BR1) and after the barrier (here, only BR4 was considered to be due to less influence of the bypass), and the carbon enrichment factor $\varepsilon_{\mathrm{C}}$ obtained in previous PCE laboratory degradation experiments with ZVI (-9.5\%o, see SD) was used. The calculated efficiency of the PRB in June-2012 was less than 10\% for PCE. This low effect of the ZVI-PRB, added to the maintenance of $\mathrm{pH}$ downgradient the barrier and the presence of chlorinated ethenes at this side of the barrier might be as a result of its non-optimal design including a too low ZVI percentage (3\%) and an insufficient size responsible of the occurrence of bypass. The effect of the PRB observed in 
June-2012 was not detected in Oct-2012 and Mar-2013 surveys, when $\delta^{13} \mathrm{C}_{\mathrm{PCE}}$ values at several points upstream of the barrier were even higher than downstream values (Fig. 4B), which seemed to indicate biodegradation at this area. These results suggested that biodegradation was the main process occurring around the ZVI-PRB. Thus, any, although low, isotopic effect due to the ZVI-PRB influence might be diluted by the higher isotopic effect produced by the biodegradation.

\subsection{Evidence of biodegradation versus ZVI-PRB-mediated degradation from the dual C- Cl isotope approach}

To confirm the predominance of biodegradation versus the low effect of the barrier, the dual ${ }^{13} \mathrm{C}-37 \mathrm{Cl}$ isotope approach for cis-DCE was used. The dual ${ }^{13} \mathrm{C}-{ }^{37} \mathrm{Cl}$ isotope plots obtained for cisDCE from the Oct-2012 data from both the upstream and downstream barrier wells yielded a dual isotope slope $\left(\varepsilon_{\mathrm{C}} / \varepsilon_{\mathrm{Cl}}\right)$ of $1.5 \pm 0.1$ (Fig. 5). The positive ${ }^{37} \mathrm{Cl}$ versus ${ }^{13} \mathrm{C}$ isotope shift correlation confirmed the occurrence of degradation processes, also through chlorine isotopes. The wells located before and after the barrier (MW17, OMW5, Pz1 from upstream and BR4-6, 7, 9, $10 \mathrm{~m}$ and Pz11 from downstream) follow the same trend within the $95 \%$ confidence interval. Therefore, it seems that the barrier is not affecting the natural biodegradation at the area close to it. The slope obtained in this study was compared to the literature data from laboratory experiments and field studies with biotic or abiotic degradation reactions of cis-DCE either as a substrate or an intermediate product ${ }^{[7,17,19]}$ (Fig. 5). The proximity of our results to the slope of 2 obtained by Hunkeler at al.[17] in a field study with cis-DCE as an intermediate and where Dehalococcoides sp. was detected points to anaerobic biodegradation as the main process occurring at the site. Since direct implication of Dehalococcoides sp. in cis-DCE degradation could not be proven in Hunkeler et al. study [17], and the slope observed in these two studies (Hunkeler et al. [17] and ours) is far from the slope of 12.5 obtained by Abe et al. [19] by the commercially available Dehalococcoides-containing KB-1 culture, it is suggested that biodegradation at both sites could be linked to a consortium of anaerobic microorganisms. 


\subsection{Extent of the natural attenuation processes}

Given that the added information from chlorine isotopes confirmed biodegradation as the main process occurring at the site, the site-specific carbon isotopic enrichment factors could be chosen to determine the extent of PCE, TCE and cis-DCE average biodegradation in the field. The $\varepsilon_{\mathrm{C}}$ values obtained for PCE and TCE from the microcosm experiments $(-2.6 \pm 0.9 \%$ and $-1.7 \pm 1.8 \%$, respectively, see details in the SD) were used to estimate the extent of natural attenuation, following Equation 3 from the SD. Despite the high uncertainty of the $\varepsilon_{\mathrm{C}}$ for TCE, this value was used to estimate the degradation because it is consistent with the literature $\varepsilon_{\mathrm{C}}$ range $(-2.5$ to $-16 \%$ ) $[9,10,11,19,32]$. However, as no cis-DCE degradation was observed in the microcosm experiments after 500 days of incubation, the $\varepsilon_{\mathrm{C}, \text { cis-DCE }}$ range reported in the literature (from -14.1 to $-29.7 \%$ ) was

used ${ }^{[9,10,13,19,32,33]}$. Although cis-DCE and TCE are intermediate compounds, their degree of biodegradation could also be determined by using Equation 3 from the SD and, by using their initial $\delta^{13} \mathrm{C}$, the original $\delta^{13} \mathrm{C}$ value of the parent compound PCE, because once the daughter product exceeds this value, the daughter product is further degraded. The lightest current ${ }^{13} \mathrm{C}$ signature of the parent compound PCE of the site $(-21.6 \%$ ) was therefore used as the initial carbon isotopic composition also for TCE and cis-DCE biodegradation degree determination. As the final isotopic composition, the concentration-weighted average of the $\delta^{13} \mathrm{C}$ values obtained from the four sampling campaigns and for each compound was used. Therefore, the average biodegradation observed was $44.5 \pm 19.3 \%$ for PCE, $70.8 \pm 30.9 \%$ for TCE and between $9.5 \pm 3.5$ and $18.9 \pm 4.0 \%$ for cis-DCE, showing that the efficiency of natural biodegradation at this field site is high and clearly above the efficiency of the ZVI-PRB.

\subsection{Use of $\delta^{13} \mathrm{C}, \delta^{37} \mathrm{Cl}$ and $\delta^{2} \mathrm{H}$ for chlorinated solvent source identification}

Based on concentration data alone, the extremely high TCE concentrations at OMW7 (139 mg/L) together with the low concentrations of TCE throughout the site suggested the presence of an additional commercial TCE source in the OMW7 groundwater flow direction. Based on our 
considerations, we would expect that TCE close to the barrier should have been formed from PCE dechlorination. This hypothesis enabled us to test in the field whether these different sources would also be distinguishable from isotopic analysis alone to check the potential of the multi-isotope approach for this purpose. Carbon isotopes showed that the less degraded PCE $\left(\delta^{13} \mathrm{C}\right.$ of $-21.6 \%$ ) was transported downstream to the ZVI-PRB area (BR1-6, Table 1 and Fig. 2). In contrast, the lowest $\delta^{13} \mathrm{C}$ of TCE (-23.4\%o) was detected in OMW7 (Table 1 and Fig. 2), west of the site. Moreover, chlorine isotope data showed that the lowest chlorine isotope values of both PCE and cis-DCE at the site were also detected in the ZVI-PRB area (BR4). This observation would confirm that remains of the less degraded PCE were present around the PRB. The positive correlation $\left(\mathrm{R}^{2}\right.$ : 0.99) between the lowest $\delta^{37} \mathrm{Cl}$ values of PCE and cis-DCE at BR4 (Fig. S6) indicated a cis-DCE coming from PCE at this point. Finally, regarding hydrogen isotope results, although the detection limits of this new technique were high ${ }^{[28]}, \delta^{2} \mathrm{H}$ of cis-DCE could still be measured in eleven samples and in the case of $\delta^{2} \mathrm{H}$ of TCE, in just one sample. The $\delta^{2} \mathrm{H}$ TCE value in the well OMW7 $\left(-91 \%\right.$ ) was not as negative as typically expected from PCE dechlorination $\left(-350 \%\right.$ o ${ }^{[25]}$, neither as positive as reported for manufactured TCEs (between +400 to $+600 \%{ }^{[25,26]}$, thus suggesting a mixture of TCE coming from PCE dechlorination and manufactured TCE.

Although the TCE concentration along the creek was too low to analyze the $\delta^{2} \mathrm{H}$, an approximation of $\delta^{2} \mathrm{H}$ data could be made. To that aim, previously, it was necessary to calculate the $\delta^{2} \mathrm{H}$ of the hydrogen added to TCE during its dechlorination to cis-DCE in OMW7 (where $\delta^{2} \mathrm{H}$ of TCE and cis-DCE is -91 and $-132 \%$, respectively) according to the equation proposed by Kuder et al. ${ }^{[24]}$

$\delta^{2} \mathrm{H}_{\text {addition }}=\left(\mathrm{n} \mathrm{x} \delta^{2} \mathrm{H}_{\text {daughter-bulk }}\right)-\left((\mathrm{n}-1) \times \delta^{2} \mathrm{H}_{\text {parent-bulk }}\right)$,

where " $n$ " is the number of hydrogen atoms in the given daughter product, the "bulk" $\delta^{2} \mathrm{H}$ refers to the average $\delta^{2} \mathrm{H}$ of parent and daughter compounds (in this case, TCE and cis-DCE, respectively). Equation 1 assumes that the protonation conserves the isotope ratios of the hydrogen inherited from the parent compound, which do not undergo hydrogen isotope exchange while residing in the 
environment ${ }^{[24]}$. The calculated value of $-173 \%$ o $\left(\delta^{2} \mathrm{H}_{\text {addition }}\right)$ allowed the estimation through the same Equation 1 of the TCE $\delta^{2} \mathrm{H}$ value in BR5-6 m where the cis-DCE $\delta^{2} \mathrm{H}$ value was known, resulting in a $\delta^{2} \mathrm{H}_{\mathrm{TCE}}$ of $-333 \%$. The presence around the barrier zone of a TCE with a very negative $\delta^{2} \mathrm{H}$ might confirm a different origin of this TCE and the TCE present in OMW7. Moreover, our estimated values are similar to the values obtained by Shouakar-Stash et al. ${ }^{[25]}$ for a TCE from PCE dechlorination $\left(\delta^{2} \mathrm{H}\right.$ of approximately -350), suggesting that TCE is coming mainly from PCE degradation, in contrast to the TCE in OMW7.

Moreover, the cis-DCE results presented, which to our knowledge are the first negative reported $\delta^{2} \mathrm{H}$ cis-DCE values, contrast with the positive values (+200\%o) of cis-DCE from reductive dechlorination of manufactured TCE in laboratory experiments ${ }^{[24]}$, enhancing the evidence that cis- $^{2}$ DCE comes mainly from the sequential reductive dechlorination from PCE at this site. Overall, although a low number of samples have been analyzed for $\delta^{2} \mathrm{H}$, the multi-isotope combination (C, $\mathrm{Cl}, \mathrm{H})$ by itself seems to have elucidated two different TCE sources at the site, one source composed of a mixture of manufactured TCE and TCE from PCE dechlorination traveling to the west (OMW7), and a second source produced mainly from PCE flowing in the creek direction. These results indicate a significant potential for the use of $\delta^{2} \mathrm{H}$ to assess the origin of industrial or degradation-derived chlorinated ethenes at contaminated sites with no other previous evidence.

\section{CONCLUSIONS}

The use of stable isotopes to monitor degradation processes at field applications is every time more developed. However, the potential of the use of hydrogen isotopes in chlorinated ethenes is just beginning to be studied. To our knowledge, until now, hydrogen isotopes of chlorinated ethenes had not been analyzed in field samples due to technical issues. In this paper we have presented a complete sequence of isotope techniques used to understand a field site contaminated by chlorinated 
ethenes 1) the use of carbon isotopes to reveal biodegradation; 2) the analyses of ${ }^{13} \mathrm{C}$ and ${ }^{37} \mathrm{Cl}$ to discriminate the main degradation process at the site; and 3) the addition of $\delta^{2} \mathrm{H}$ to provide new knowledge on this field that seems to be very promising. However, the recently reported negative $\delta^{2} \mathrm{H}$ values (up to $-184 \%$ ) ${ }^{[24]}$ of manufactured TCE, could be a limitation of this technique. Nevertheless, the high depletion in ${ }^{2} \mathrm{H}$ observed during TCE formation in the environment may still be a potential way to discriminate the origin of TCE and cis-DCE.

\section{SUPPLEMENTARY DATA}

The site study description, groundwater sampling, chlorinated ethene analyses, analyses of ethene, ethane and acetylene compounds, complementary microcosm experiments, experiment of PCE degradation with ZVI and more information from $\delta^{37} \mathrm{Cl}$ and $\delta^{2} \mathrm{H}$ data are included in the Supplementary Data, as well as complementary figures and tables commented upon in the main text.

\section{ACKNOWLEDGMENTS}

This study was funded by the Spanish Government CICYT projects CGL2011-29975-C04-01 and CGL2014-57215-C4-1-R, by the Catalan Government project 2014 SGR 1456 and a Marie Curie Career Integration Grant in the framework of the IMOTEC-BOX project (PCIG9-GA-2011293808) within the European Union $7^{\text {th }}$ Framework Programme. The authors want to thank Clapé Group for providing us with the used zero-valent iron, financing the installation of the multilevel wells and contracting us to study the ZVI-PRB efficiency as well as allowing this publication. We would like to thank the Catalan Water Agency for their support, and the Institute of Groundwater Ecology from the "Helmholtz Zentrum München', the Isotope Trace Technologies from Waterloo, the Stable Isotope Laboratory from the University of Toronto, and the "Centres Científics i 
Tecnològics de la Universitat de Barcelona" for the chemical analyses. We want to thank Daniel Sancho, Roberto Espinola, Adriana Rossi, Diana Rodríguez, Alba Grau, Mercè de Olamendi and Raul Carrey for helping in the field surveys. Special thanks to Joan Martínez from "GEOMAR Enginyeria del Terreny", for the installation of the well OMW7.

\section{REFERENCES}

[1] J.S. Zogorski, J.M. Carter, T. Ivahnenko, W.W. Lapham, M.J. Moran, B.L. Rowe, P.J. Squillace, P.L. Toccalino, Volatile Organic Compounds in the Nation's Ground Water and Drinking-Water Supply Wells. 2006. U.S. Geological Survey, Reston, Virginia. Circular 1292.

[2] A.K. Friis, H.J. Albrechtsen, E.Cox, P.L. Bjerg, The need for bioaugmentation after thermal treatment of a TCE-contaminated aquifer: Laboratory experiments. J Contam Hydrol. 88 (2006) (34) $235-48$

[3] United States Environmental Protection Agency, National primary drinking water regulations. EPA 816-F-09-004 2009. http://water.epa.gov/drink/contaminants/upload/mcl.pdf.

[4] M.M. Scherer, S. Richter, R.L. Valentine, P.J.J. Alvarez, Chemistry and Microbiology of Permeable Reactive Barriers for In Situ Groundwater Clean up. Environ. Sci. Technol. 30 (2000) (3), 363-411

[5] W.A. Arnold, A.L. Roberts, Pathways and kinetics of chlorinated ethylene and chlorinated acetylene reaction with Fe(0) particles. Environ. Sci. Technol. 34 (2000) 1794-1805. 
[6] M. Elsner, M. Chartrand, N. Vanstone, G. Lacrampe-Couloume, B. Sherwood Lollar, Identifying abiotic chlorinated ethene degradation: characteristic isotope patterns in reaction products with nanoscale zero-valent iron. Environ. Sci. Technol. 42 (2008) 5963-5970.

[7] C. Audí-Miró, S. Cretnik, N. Otero, J. Palau, O. Shouakar-Stash, A. Soler, M. Elsner, Cl and C isotope analysis to assess the effectiveness of chlorinated ethene degradation by zero-valent iron: Evidence from dual element and product isotope values. Appl. Geochem. 32 (2013) 175-183

[8] B. Sherwood-Lollar, G.F. Slater, J. Ahad, B. Sleep, J. Spivack, M. Brennan, P. Mackenzie, Contrasting carbon isotope fractionation during biodegradation of trichloroethylene and toluene: Implications for intrinsic bioremediation. Org. Geochem. 30 (1999) 813-820

[9] Y. Bloom, R. Aravena, D. Hunkeler, E. Edwards, S.K. Frape, Carbon Isotope Fractionation during Microbial Dechlorination of Trichloroethene, cis-1,2-Dichloroethene, and Vinyl Chloride: Implications for Assessment of Natural Attenuation. Environ. Sci. Technol. 34 (2000) 2768-2772

[10] G.F. Slater, B. Sherwood-Lollar, B. Sleep, E. Edwards, Variability in Carbon Isotopic Fractionation during Biodegradation of Chlorinated Ethenes: Implications for Field Applications. Environ. Sci. Technol. 35 (2001) 901-907

[11] X. Liang, Y. Dong, T. Kuder, L. R. Krumholz, R. P. Philp, E. C. Butler, Distinguishing abiotic and biotic transformation of tetrachloroethylene and trichloroethylene by stable carbon isotope fractionation. Environ. Sci. Technol. 41 (2007) (20), 7094-7100.

[12] K.R. Schmidt, T. Augenstein, M. Heidinger, S. Ertl, A. Tiehm, Aerobic biodegradation of cis1,2-dichloroethene as sole carbon source: Stable carbon isotope fractionation and growth characteristics. Chemosphere. 78 (2010) 527-532 
[13] K.E. Fletcher, I. Nijenhuis, H-H. Richnow, F.E. Löffler, Stable Carbon Isotope Enrichment Factors for cis-1,2-Dichloroethene and Vinyl Chloride Reductive Dechlorination by Dehalococcoides. Environ. Sci. Technol. 45 (2011) 2951-2957

[14] H. Dayan, T. Abrajano, N.C. Sturchio, L. Winsor, Carbon isotopic fractionation during reductive dehalogenation of chlorinated ethenes by metallic iron. Org. Geochem. 30 (1999) 755763.

[15] G.F. Slater, B.S. Lollar, A. King, S. O’Hannesin, Isotopic fractionation during reductive dechlorination of trichloroethene by zero-valent iron: influence of surface treatment. Chemosphere. 49 (2002) 587-596.

[16] N.A. Vanstone, R.M. Focht, S.A. Mabury, B. Sherwood Lollar, Effect of iron type on kinetics and carbon isotopic enrichment of chlorinated ethylenes during abiotic reduction on $\mathrm{Fe}(0)$. Ground Water. 42 (2004) 268-276.

[17] D. Hunkeler, Y. Abe, M.M. Broholm, S. Jeannottat, C. Westergaard, C.S. Jacobsen, R. Aravena, P.L. Bjerg, Assessing chlorinated ethene degradation in a large scale contaminant plume by dual carbon-chlorine isotope analysis and quantitative PCR. J. Contam. Hydrol. 119 (2011) 6979.

[18] M. Elsner, L. Zwank, D. Hunkeler, A.P. Schwarzenbach, A new concept linking observable stable isotope fractionation to transformation pathways of organic pollutants. Environ. Sci. Technol. 39 (2005) 6896-6916. 
[19] Y. Abe, R. Aravena, J. Zopfi, O. Shouakar-Stash, E. Cox, J.D. Roberts, D. Hunkeler, Carbon and chlorine isotope fractionation during aerobic oxidation and reductive dechlorination of vinyl chloride and cis-1,2-dichloroethene. Environ. Sci. Technol. 43 (2009) 101-107.

[20] O. Shouakar-Stash, R.J. Drimmie, M. Zhang, S.K. Frape, Compound-specific chlorine isotope ratios of TCE, PCE and DCE isomers by direct injection using CFIRMS. Appl. Geochem. 21 (2006) 766-781.

[21] P. Lojkasek-Lima, R. Aravena, O. Shouakar-Stash, S.K. Frape, M. Marchesi, S. Fiorenza, J. Vogan, Evaluating TCE abiotic and biotic degradation pathways in a permeable reactive barrier using compound specific isotope analysis. Ground Water. 32 (2012) 53-62

[22] C. Wiegert, M. Mandalakis, T. Knowles, P.N. Polymenakou, C. Aeppli, J. Macháčková, H. Holmstrand, R. Evershed, R.D. Pancost, O. Gustafsson, Carbon and Chlorine Isotope Fractionation During Microbial Degradation of Tetra- and Trichloroethene. Environ. Sci. Technol. 47 (2013) 6449-6456

[23] S. Cretnik, K.A. Thoreson, A. Bernstein, K. Ebert, D. Buchner, C. Laskov, S. Haderlein, O. Shouakar-Stash, S. Kliegman, K. McNeill, M. Elsner, Reductive dechlorination of TCE by chemical model systems in comparison to dehalogenating bacteria: Insights from dual element isotope analysis $\left({ }^{13} \mathrm{C} /{ }^{12} \mathrm{C},{ }^{37} \mathrm{Cl} /{ }^{35} \mathrm{Cl}\right)$. Environ. Sci. Technol. 47 (2013) 6855-6863.

[24] T. Kuder, B.M. van Breukelen, M. Vanderford, P. Philp, 3D-CSIA: Carbon, Chlorine, and Hydrogen Isotope Fractionation in Transformation of TCE to Ethene by a Dehalococcoides Culture. Environ. Sci. Technol. 47 (2013) 9668-9677 
[25] O. Shouakar-Stash, S.K. Frape, R.J. Drimmie, Stable hydrogen, carbon and chlorine isotope measurements of selected chlorinated organic solvents. J. Contam. Hydrol. 60 (2003) 211- 228

[26] S. Ertl, F. Seibel, L. Eichinger, F. H. Frimmel, A. Kettrup, The C-13/C-12 and H-2/H-1 ratios of trichloroethene, tetrachloroethene and their metabolites. Isot. Environ. Health Stud. 34 (1998) (3), 245-253.

[27] C. Torrentó, C. Audí-Miró, G. Bordeleau, M. Marchesi, M. Rosell, N. Otero, A. Soler, The use of alkaline hydrolysis as a novel strategy for chloroform remediation: feasibility of using urban construction wastes and evaluation of carbon isotopic fractionation. Environ. Sci. Technol. 48 (2014) (3) 1869-1877

[28] O. Shouakar-Stash, R.J. Drimmie, Online methodology for determining compound-specific hydrogen stable isotope ratios of trichloroethene and 1,2-cis-dichloroethene by continuous-flow isotope ratio mass spectrometry. Rapid Commun. Mass Spectrom. 27 (2013) 1335-1344

[29] T. Suponik, Groundwater treatment with the use of zero-valent iron in the permeable reactive barrier technology. Physicochem. Probl. Min. Process. 49 (2013) (1), 13-23

[30] E.M. van Warmerdam, S.K. Frape, R. Aravena, R.J. Drimmie, H. Flatt, J.A. Cherry, Stable chlorine and carbon isotope measurements of selected chlorinated organic solvents. Appl. Geochem. 10 (1995) 547-552

[31] N. Jendrzejewski, H.G.M. EggenKamp, M.N. Coleman, Characterization of chlorination hydrocarbons from chlorine and carbon isotopic compositions: scope of application to environmental problems. Appl. Geochem. 16 (2001) 1021-1031 
[32] J.W. Lee, D.K. Cha, Y.K. Oh, K.B. Ko, S.H. Jin, Wastewater screening method for evaluating applicability of zero-valent iron to industrial wastewater. J. Hazard. Mater. 180 (2010) 354-360

[33] D. Hunkeler, R. Aravena, E. Cox, Carbon isotopes as a tool to evaluate the origin and fate of vinyl chloride: Laboratory experiments and modeling of isotope evolution. Environ. Sci. Technol. 36 (2002) (15), 3378-3384

\section{FIGURE CAPTIONS}

Figure 1. Wells distribution. A) Map of the study site. The location of the wells installed along the Can Ninou Creek and the location of the ZVI PRB, as well as the piezometric surfaces and groundwater flow lines are represented. B) Distribution of the multilevel wells around the ZVIPRB. C) Cross section along the creek from the source area to $900 \mathrm{~m}$ downstream. The lithology of each well is exposed, as well as the water table indicated by the green triangles. cis-DCE concentration contours are also shown.

Figure 2. C, $\mathbf{C l}$ and $\mathbf{H}$ isotope data distribution. Isotope data of: $\delta^{13} \mathrm{C}$ and $\delta^{37} \mathrm{Cl}$ of PCE (A and B, respectively) $\delta^{13} \mathrm{C}$ of TCE (C) and $\delta^{13} \mathrm{C}, \delta^{37} \mathrm{Cl}$ and $\delta^{2} \mathrm{H}$ of cis-DCE (D, E and F, respectively). F also includes TCE data, indicated in blue. These isotope data have been obtained from the most representative wells from: 1) the last survey (Mar-2013) in the case of $\delta^{13} \mathrm{C}$ data (except for the wells in red for $\delta^{13} \mathrm{C}$ of PCE that are from Jun-2012) and from 2) the only survey when $\delta^{2} \mathrm{H}$ and $\delta^{37} \mathrm{Cl}$ were measured, Oct-2012. OMW7 $\delta^{13} \mathrm{C}$ and $\delta^{2} \mathrm{H}$ data are from Sept-2013. 
Figure 3. Time evolution of $\mathbf{C}$ isotopes. Changes in $\delta^{13} \mathrm{C}$ over time of PCE and cis-DCE in wells OMW5 and BR1-11, and MW17 and BR1-9.5, respectively. Error bars represent $\delta^{13} \mathrm{C}$ uncertainty of $0.5 \%$.

Figure 4. C isotopes at the ZVI-PRB. $\delta^{13} \mathrm{C}$ of PCE in BR1 (blue squares, directly upstream from the ZVI-PRB), BR3 (red diamonds) and BR4 (green triangles) (both directly behind the ZVI-PRB) in depth from June-2012 (A) and Mar-2013 (B) campaigns. Error bars represent an uncertainty of $0.5 \%$ for $\delta^{13} \mathrm{C}$ measurements (for location of wells, see Figure 1).

Figure 5. Dual isotope plot C-Cl. $\delta^{13} \mathrm{C}$ versus $\delta^{37} \mathrm{Cl}$ from Oct-2012 campaign samples. A dual isotope slope $\left(\varepsilon_{\mathrm{C}} \varepsilon_{\mathrm{Cl}}\right)$ of $1.5 \pm 0.1$ was determined. Red diamonds represent wells upstream of the ZVI-PRB, and green squares represent wells downstream from the ZVI-PRB. Blue lines indicate the $95 \%$ confidence intervals of the regression line. Dashed lines show the slopes obtained in previous studies: 1) cis-DCE substrate in Abe et al. $\beta$-Proteobacterium spp. batch experiments ${ }^{[19]} 2$ ) cis-DCE substrate in Abe et al. Dehaloccocoides KB-1 batch experiments ${ }^{[19]}$ 3) cis-DCE

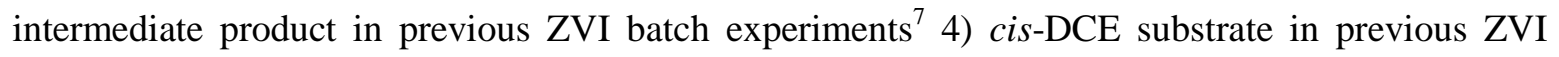

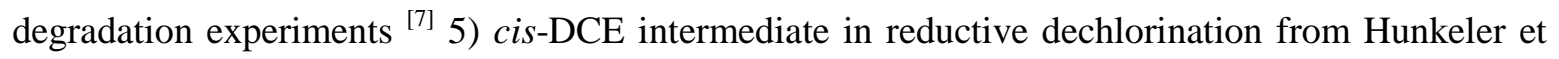
al. field studies ${ }^{[17]}$.

\section{TABLE CAPTIONS}

Table 1. Concentration and isotope data for the main compounds of the site obtained from the groundwater sampling campaigns conducted from April 2011 to March 2013. ${ }^{1}=$ distance from the source n.a. $=$ not analyzed n.d. $=$ not detected. Uncertainty is $0.5 \%$ for $\delta^{13} \mathrm{C}, 0.2 \% \circ$ for $\delta^{37} \mathrm{Cl}$ and between 2 and $26 \%$ ofor $\delta^{2} \mathrm{H}$ measurements. Concentration uncertainty is $10 \%$. 


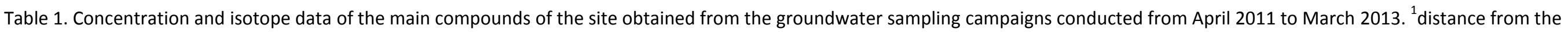

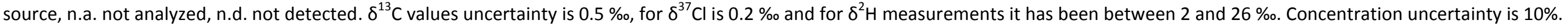

\begin{tabular}{|c|c|c|c|c|c|c|c|c|c|c|c|c|c|c|c|c|c|c|c|c|c|c|c|c|c|c|c|c|c|c|c|c|c|c|c|c|c|c|}
\hline & \multicolumn{26}{|c|}{ Upgradient the ZVI-PRB } & \multirow{2}{*}{\multicolumn{4}{|c|}{\begin{tabular}{|c|} 
W from the ZVI-PRB \\
Pz4. $330 \mathrm{~m}^{1}$ \\
\end{tabular}}} & \multicolumn{8}{|c|}{ Downgradient the ZVI-PRB } \\
\hline & \multicolumn{4}{|c|}{ MW17. $23 \mathrm{~m}^{1}$} & \multicolumn{4}{|c|}{ OMW5. $60 \mathrm{~m}^{1}$} & \multirow{2}{*}{$\begin{array}{c}\text { oMw6B. } 7 \mathrm{~m}^{1} \\
\frac{7}{7} \\
\frac{1}{8}\end{array}$} & \multirow{2}{*}{ 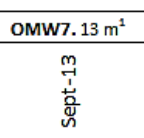 } & \multicolumn{4}{|c|}{ Pz1. $100 \mathrm{~m}^{1}$} & \multicolumn{4}{|c|}{ P22. $200 \mathrm{~m}^{1}$} & \multicolumn{4}{|c|}{ P23. $280 \mathrm{~m}^{1}$} & \multicolumn{4}{|c|}{ Pz10. $320 \mathrm{~m}^{1}$} & & & & & \multicolumn{4}{|c|}{ Pz11. $326 \mathrm{~m}^{1}$} & \multicolumn{4}{|c|}{ Pz7. $500 \mathrm{~m}^{2}$} \\
\hline & $\frac{7}{\frac{7}{2}}$ & 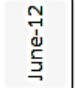 & \begin{tabular}{l}
\multirow{2}{t}{} \\
$\dot{t}$ \\
$\mathrm{o}$
\end{tabular} & $\begin{array}{l}\frac{m}{\frac{m}{1}} \\
\frac{i}{\tilde{N}}\end{array}$ & $\overrightarrow{\overline{1}}$ & 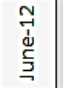 & $\begin{array}{l}7 \\
\dot{I} \\
\mathrm{o}\end{array}$ & $\begin{array}{l}\frac{m}{7} \\
\frac{7}{1} \\
\frac{10}{2}\end{array}$ & & & $\frac{\overrightarrow{1}}{\frac{1}{2}}$ & 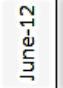 & $\begin{array}{l}7 \\
\dot{I} \\
\mathrm{t}\end{array}$ & $\frac{m}{\frac{m}{1}}$ & $\frac{7}{\frac{1}{2}}$ & 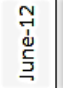 & \begin{tabular}{l}
\multirow{1}{t}{} \\
$\dot{t}$ \\
$\mathrm{o}$
\end{tabular} & 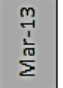 & $\frac{\overrightarrow{1}}{\frac{1}{2}}$ & 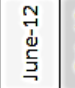 & \begin{tabular}{l}
\multirow{7}{t}{} \\
$\dot{t}$ \\
$\mathrm{o}$
\end{tabular} & $\frac{m}{\frac{m}{1}}$ & $\overrightarrow{\frac{1}{2}}$ & 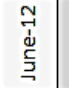 & \begin{tabular}{l}
\multirow{I}{t}{} \\
$\stackrel{\Delta}{0}$
\end{tabular} & $\begin{array}{l}\frac{m}{\frac{m}{1}} \\
\frac{1}{m} \\
\sum\end{array}$ & $\overrightarrow{\overrightarrow{1}}$ & 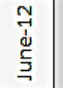 & \begin{tabular}{l}
\multirow{7}{t}{} \\
$\dot{t}$
\end{tabular} & $\begin{array}{l}\frac{m}{1} \\
\frac{1}{10} \\
\frac{1}{2}\end{array}$ & $\overrightarrow{\frac{1}{3}}$ & $\begin{array}{l}\stackrel{̃}{\dot{d}} \\
\stackrel{\underline{\Xi}}{\xi}\end{array}$ & \begin{tabular}{l}
\multirow{I}{t}{} \\
$\mathrm{t}$
\end{tabular} & $\begin{array}{l}\frac{m}{1} \\
\frac{i}{\frac{1}{n}} \\
\sum\end{array}$ & $\frac{\overrightarrow{7}}{\frac{1}{2}}$ & 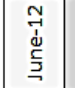 & $\underset{\stackrel{I}{t}}{\mathrm{t}}$ & 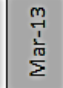 \\
\hline $\begin{array}{cc}\mathrm{gg} / \mathrm{L} \\
\text { U. } \\
\delta^{13} \mathrm{C}(\%) \\
\delta^{33} \mathrm{Cl}(\%) \\
\end{array}$ & $\begin{array}{l}<.6 \\
\text { n.d. } \\
\text { n.a. }\end{array}$ & \begin{tabular}{l|l|}
$<2.6$ \\
n.d. \\
n.a. \\
\end{tabular} & $\begin{array}{l}<2.6 \\
\text { n.d. } \\
\text { n.a. } \\
\end{array}$ & $\begin{array}{l}28 \\
\text { n.d. } \\
\text { n.a. }\end{array}$ & $\begin{array}{c}38 \\
-20.7 \\
\text { n.a. } \\
\end{array}$ & $\begin{array}{c}58 \\
-20.0 \\
\text { n.a. } \\
\end{array}$ & \begin{tabular}{c|}
127 \\
-19.9 \\
0.5 \\
\end{tabular} & \begin{tabular}{|l|}
246 \\
-19.1 \\
n.a. \\
\end{tabular} & $\begin{array}{l}178 \\
-19.6 \\
\text { n.a. } \\
\end{array}$ & $\begin{array}{l}<2.6 \\
\text { n.d. } \\
\text { n.a. }\end{array}$ & \begin{tabular}{|l|}
$<2.6$ \\
n.d. \\
n.a. \\
\end{tabular} & $\begin{array}{l}<.6 \\
\text { n.d. } \\
\text { n.a. } \\
\end{array}$ & $\begin{array}{l}<2.6 \\
\text { n.d. } \\
\text { n.a. } \\
\end{array}$ & \begin{tabular}{c|c|}
27 & \\
-19.9 & - \\
n.a. & \\
\end{tabular} & \begin{tabular}{c|c}
123 & \\
-19.6 & - \\
n.a. & \\
\end{tabular} & $\begin{array}{c}90 \\
-19.7 \\
\text { n.a. } \\
\end{array}$ & \begin{tabular}{|l|} 
n.a. \\
n.a. \\
n.a. \\
\end{tabular} & $\begin{array}{c}517 \\
-19.8 \\
\text { n.a. }\end{array}$ & \begin{tabular}{|c|}
329 \\
-20.0 \\
n.a. \\
\end{tabular} & \begin{tabular}{|c|c|}
253 & $n$ \\
-19.6 & $n$ \\
n.a. & $n$ \\
\end{tabular} & \begin{tabular}{|l|} 
n.a. \\
n.a. \\
n.a. \\
\end{tabular} & $\begin{array}{l}11 \\
\text { n.d. } \\
\text { n.a. }\end{array}$ & \begin{tabular}{|c|}
48 \\
-19.8 \\
n.a. \\
\end{tabular} & \begin{tabular}{c|}
703 \\
-20.3 \\
n.a. \\
\end{tabular} & \begin{tabular}{c|}
917 \\
-20.1 \\
0.2 \\
\end{tabular} & \begin{tabular}{|c|}
145 \\
-19.2 \\
n.a. \\
\end{tabular} & \begin{tabular}{|c|c|}
7 & 3 \\
n.d. & -1 \\
n.a. & r \\
\end{tabular} & \begin{tabular}{c|c}
391 \\
-19.9 \\
n.a.
\end{tabular} & \begin{tabular}{l|l} 
n.a. \\
n.a. \\
n.a.
\end{tabular} & $\begin{array}{c}49 \\
-20.4 \\
\text { n.a. }\end{array}$ & \begin{tabular}{c|}
80 \\
-19.9 \\
n.a.
\end{tabular} & \begin{tabular}{c|}
209 \\
-19.5 \\
n.a.
\end{tabular} & \begin{tabular}{c|c}
158 \\
-19.3 \\
0.4 \\
\end{tabular} & $\begin{array}{c}27 \\
-20.2 \\
\text { n.a. }\end{array}$ & \begin{tabular}{c|}
$<2.6$ \\
n.d. \\
n.a.
\end{tabular} & \begin{tabular}{|c|}
5 \\
-20.6 \\
n.a. \\
\end{tabular} & \begin{tabular}{c|}
3 \\
n.d. \\
n.a. \\
\end{tabular} & $\begin{array}{c}5 \\
\text { n.d. } \\
\text { n.a. }\end{array}$ \\
\hline $\begin{array}{cc}\mu \mathrm{g} / \mathrm{L} \\
\underset{\vdash}{U} & \delta^{13} \mathrm{C}(\%) \\
& \delta^{2} \mathrm{H}(\%) \\
\end{array}$ & $\begin{array}{l}<2.6 \\
\text { n.d. } \\
\text { n.a. }\end{array}$ & $\begin{array}{l}<2.6 \\
\text { n.d. } \\
\text { n.a. } \\
\end{array}$ & \begin{tabular}{l|l}
$<2.6$ \\
n.d. \\
n.a. \\
\end{tabular} & $\begin{array}{l}26 \\
\text { n.d. } \\
\text { n.a. }\end{array}$ & $\begin{array}{c}17 \\
-19.9 \\
\text { n.a. } \\
\end{array}$ & $\begin{array}{l}<2.6 \\
\text { n.d. } \\
\text { n.a. }\end{array}$ & $\begin{array}{l}<2.6 \\
\text { n.d. } \\
\text { n.a. }\end{array}$ & \begin{tabular}{|c|}
74 \\
-20.6 \\
n.a. \\
\end{tabular} & $\begin{array}{c}4072 \\
-19.9 \\
\text { n.a. }\end{array}$ & $\begin{array}{c}139336 \\
-23.4 \\
-91\end{array}$ & \begin{tabular}{|c|}
11 \\
-20.0 \\
n.a.
\end{tabular} & \begin{tabular}{l|}
$<2.6$ \\
n.d. \\
n.a.
\end{tabular} & \begin{tabular}{l|}
$<2.6$ \\
n.d. \\
n.a.
\end{tabular} & $\begin{array}{c}8 \\
\text { n.d. } \\
\text { n.a. }\end{array}$ & \begin{tabular}{c|c}
24 & \\
-16.0 & - \\
n.a. & \\
\end{tabular} & \begin{tabular}{c|}
11 \\
-13.5 \\
n.a. \\
\end{tabular} & \begin{tabular}{|l|} 
n.a. \\
n.a. \\
n.a. \\
\end{tabular} & $\begin{array}{c}44 \\
\text { n.d. } \\
\text { n.a. }\end{array}$ & \begin{tabular}{|c|}
3 \\
n.d. \\
n.a. \\
\end{tabular} & \begin{tabular}{|c|c|c}
15 & $n$ \\
-12.2 & $n$ \\
n.a. & $n$ \\
\end{tabular} & \begin{tabular}{|l|} 
n.a. \\
n.a. \\
n.a. \\
\end{tabular} & $\begin{array}{l}56 \\
\text { n.d. } \\
\text { n.a. }\end{array}$ & \begin{tabular}{|c|}
$<2.6$ \\
n.d. \\
n.a.
\end{tabular} & $\begin{array}{c}7 \\
\text { n.d. } \\
\text { n.a. } \\
\end{array}$ & $\begin{array}{l}<2,6 \\
\text { n.d. } \\
\text { n.a. }\end{array}$ & $\begin{array}{l}<2,6 \\
\text { n.d. } \\
\text { n.a. } \\
\end{array}$ & 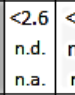 & \begin{tabular}{l|}
$<2.6$ \\
n.d. \\
n.a.
\end{tabular} & \begin{tabular}{|c|} 
n.a. \\
n.a. \\
n.a.
\end{tabular} & $\begin{array}{c}<2,6 \\
\text { n.d. } \\
\text { n.a. }\end{array}$ & $\begin{array}{c}<2.6 \\
\text { n.d. } \\
\text { n.a. }\end{array}$ & $\begin{array}{c}7 \\
\text { n.d. } \\
\text { n.a. }\end{array}$ & \begin{tabular}{c|}
3 \\
n.d. \\
n.a.
\end{tabular} & $\begin{array}{c}<2,6 \\
\text { n.d. } \\
\text { n.a. }\end{array}$ & \begin{tabular}{c|}
$<2.6$ \\
n.d. \\
n.a.
\end{tabular} & \begin{tabular}{|c|}
$<2.6$ \\
n.d. \\
n.a.
\end{tabular} & \begin{tabular}{c|}
5 \\
n.d. \\
n.a.
\end{tabular} & \begin{tabular}{|l|}
$<2,6$ \\
n.d. \\
n.a.
\end{tabular} \\
\hline $\begin{array}{ccc} & \mu \mathrm{g} / \mathrm{L} \\
\Psi & \delta^{13} \mathrm{C}(\%) \\
\square & \delta^{37} \mathrm{Cl}(\%) \\
& \delta^{2} \mathrm{H}(\% 0)\end{array}$ & $\begin{array}{c}45735 \\
-19.9 \\
\text { n.a. } \\
\text { n.a. } \\
\end{array}$ & \begin{tabular}{|c|}
16745 \\
-19.9 \\
n.a. \\
n.a. \\
\end{tabular} & \begin{tabular}{|c|}
18010 \\
-18.3 \\
3.8 \\
-222 \\
\end{tabular} & $\begin{array}{c}28681 \\
-15.7 \\
\text { n.a. } \\
\text { n.a. } \\
\end{array}$ & \begin{tabular}{c|}
104 \\
-22.0 \\
n.a. \\
n.a. \\
\end{tabular} & \begin{tabular}{c|}
166 \\
-20.0 \\
n.a. \\
n.a. \\
\end{tabular} & \begin{tabular}{c|}
266 \\
-19.2 \\
3.3 \\
-198 \\
\end{tabular} & \begin{tabular}{|c|}
188 \\
-19.9 \\
n.a. \\
n.a. \\
\end{tabular} & $\begin{array}{l}<2.6 \\
\text { n.d. } \\
\text { n.a. } \\
\text { n.a. }\end{array}$ & $\begin{array}{c}21740 \\
-27.8 \\
\text { n.a. } \\
-132 \\
\end{array}$ & \begin{tabular}{|c|}
13 \\
-17.9 \\
n.a. \\
n.a. \\
\end{tabular} & \begin{tabular}{c|}
54 \\
-16.8 \\
n.a. \\
n.a. \\
\end{tabular} & \begin{tabular}{c|}
530 \\
-17.5 \\
5.2 \\
n.a. \\
\end{tabular} & \begin{tabular}{|c|c}
33 & \\
-15.2 & - \\
n.a. \\
n.a. \\
\end{tabular} & \begin{tabular}{c|c}
861 & 7 \\
-14.7 & -1 \\
n.a. & \\
n.a. & \\
\end{tabular} & \begin{tabular}{c|}
720 \\
-19.7 \\
n.a. \\
n.a. \\
\end{tabular} & \begin{tabular}{l|} 
n.a. \\
n.a. \\
n.a. \\
n.a. \\
\end{tabular} & \begin{tabular}{c|}
1328 \\
-20.2 \\
n.a. \\
n.a. \\
\end{tabular} & \begin{tabular}{|c|}
88 \\
-17.4 \\
n.a. \\
n.a. \\
\end{tabular} & \begin{tabular}{|c|l|}
479 & $n$ \\
-21.2 & $n$ \\
n.a. & $n$ \\
n.a. & $n$ \\
\end{tabular} & \begin{tabular}{|l|l} 
n.a. & \\
n.a. & - \\
n.a. & \\
n.a. & \\
\end{tabular} & \begin{tabular}{c|}
218 \\
-17.7 \\
n.a. \\
n.a. \\
\end{tabular} & \begin{tabular}{|c|}
17 \\
-15.5 \\
n.a. \\
n.a. \\
\end{tabular} & \begin{tabular}{c|}
191 \\
-20.9 \\
n.a. \\
n.a. \\
\end{tabular} & \begin{tabular}{c|}
154 \\
-17.5 \\
3.6 \\
n.a. \\
\end{tabular} & \begin{tabular}{|c|}
15 \\
-16.6 \\
n.a. \\
n.a. \\
\end{tabular} & \begin{tabular}{|c|c}
$<2.6$ & \\
n.d. & -1 \\
n.a. & n. \\
n.a. & r \\
\end{tabular} & \begin{tabular}{c|}
21 \\
-11.3 \\
n.a. \\
n.a. \\
\end{tabular} & \begin{tabular}{l|} 
n.a. \\
n.a. \\
n.a. \\
n.a. \\
\end{tabular} & $\begin{array}{c}3 \\
-14.8 \\
\text { n.a. } \\
\text { n.a. } \\
\end{array}$ & \begin{tabular}{c|}
7 \\
-11.6 \\
n.a. \\
n.a. \\
\end{tabular} & \begin{tabular}{c|}
99 \\
-18.2 \\
n.a. \\
n.a. \\
\end{tabular} & \begin{tabular}{c|}
251 \\
-16.4 \\
4.7 \\
-187 \\
\end{tabular} & $\begin{array}{c}27 \\
-15.2 \\
\text { n.a. } \\
\text { n.a. } \\
\end{array}$ & \begin{tabular}{c|}
5 \\
n.d. \\
n.a. \\
n.a. \\
\end{tabular} & \begin{tabular}{|c|}
3 \\
n.d. \\
n.a. \\
n.a. \\
\end{tabular} & \begin{tabular}{c|}
3 \\
n.d. \\
n.a. \\
n.a. \\
\end{tabular} & \begin{tabular}{|c|}
18 \\
-15.8 \\
n.a. \\
n.a. \\
\end{tabular} \\
\hline$Y \begin{array}{c}\mu \mathrm{g} / \mathrm{L} \\
\delta^{13} \mathrm{C}(\%)\end{array}$ & $\begin{array}{l}\text { n.a. } \\
\text { n.a. }\end{array}$ & $\begin{array}{c}7886 \\
\text { n.a. } \\
\end{array}$ & $\begin{array}{l}247 \\
\text { n.a. } \\
\end{array}$ & $\begin{array}{r}1280 \\
-38.4 \\
\end{array}$ & \begin{tabular}{|l|} 
n.a. \\
n.a. \\
\end{tabular} & \begin{tabular}{c|c|}
5 \\
n.a. \\
\end{tabular} & \begin{tabular}{l|}
$<2.6$ \\
n.d. \\
\end{tabular} & \begin{tabular}{|l|}
$<2.6$ \\
n.d.
\end{tabular} & $\begin{array}{l}\text { n.a. } \\
\text { n.a. }\end{array}$ & $\begin{array}{l}<2.6 \\
\text { n.a. }\end{array}$ & \begin{tabular}{|l|} 
n.a. \\
n.a. \\
\end{tabular} & \begin{tabular}{l|}
$<2.6$ \\
n.d. \\
\end{tabular} & \begin{tabular}{l|}
$<2.6$ \\
n.d.
\end{tabular} & \begin{tabular}{|l|l|}
$<2.6$ \\
n.d.
\end{tabular} & \begin{tabular}{l|l} 
n.a. & $<$ \\
n.a. & \\
\end{tabular} & \begin{tabular}{l|}
$<2.6$ \\
n.a. \\
\end{tabular} & \begin{tabular}{|l|} 
n.a. \\
n.a. \\
\end{tabular} & \begin{tabular}{l|}
$<2.6$ \\
n.a. \\
\end{tabular} & \begin{tabular}{|l|} 
n.a. \\
n.a. \\
\end{tabular} & \begin{tabular}{|l|l|}
$<2.6$ & $n$ \\
n.a. & $n$ \\
\end{tabular} & \begin{tabular}{|l|} 
n.a. \\
n.a. \\
\end{tabular} & \begin{tabular}{c|}
114 \\
-20.4 \\
\end{tabular} & $\begin{array}{l}\text { n.a. } \\
\text { n.a. }\end{array}$ & $\begin{array}{l}<2.6 \\
\text { n.a. } \\
\end{array}$ & \begin{tabular}{l|}
$<2.6$ \\
n.d. \\
\end{tabular} & \begin{tabular}{|l|}
$<2.6$ \\
n.d. \\
\end{tabular} & \begin{tabular}{|l|l|} 
n.a. & $<$ \\
n.a. & . \\
\end{tabular} & \begin{tabular}{l|l}
$<2.6$ & \\
n.a.
\end{tabular} & $\begin{array}{ll}\text { n.a. } \\
\text { n.a. }\end{array}$ & $\begin{array}{l}2.6 \\
\text { n.a. }\end{array}$ & $\begin{array}{l}\text { n.a. } \\
\text { n.a. } \\
\end{array}$ & $\begin{array}{c}7 \\
\text { n.a. } \\
\end{array}$ & \begin{tabular}{l|}
$<2.6$ \\
n.d.
\end{tabular} & $\begin{array}{l}<2.6 \\
\text { n.d. } \\
\end{array}$ & \begin{tabular}{|l|} 
n.a. \\
n.a. \\
\end{tabular} & \begin{tabular}{|l|}
$<2.6$ \\
n.a.
\end{tabular} & \begin{tabular}{l|}
$<2.6$ \\
n.d. \\
\end{tabular} & $\begin{array}{l}<.6 \\
\text { n.d. } \\
\end{array}$ \\
\hline
\end{tabular}

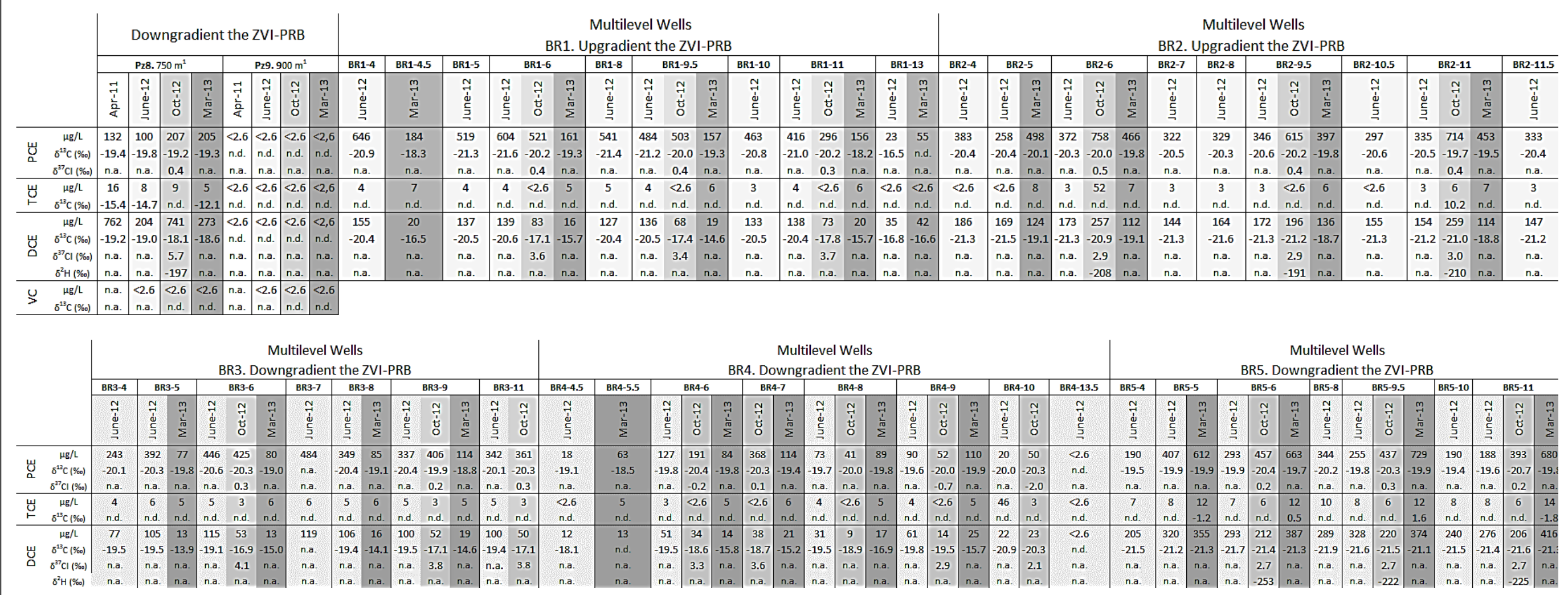



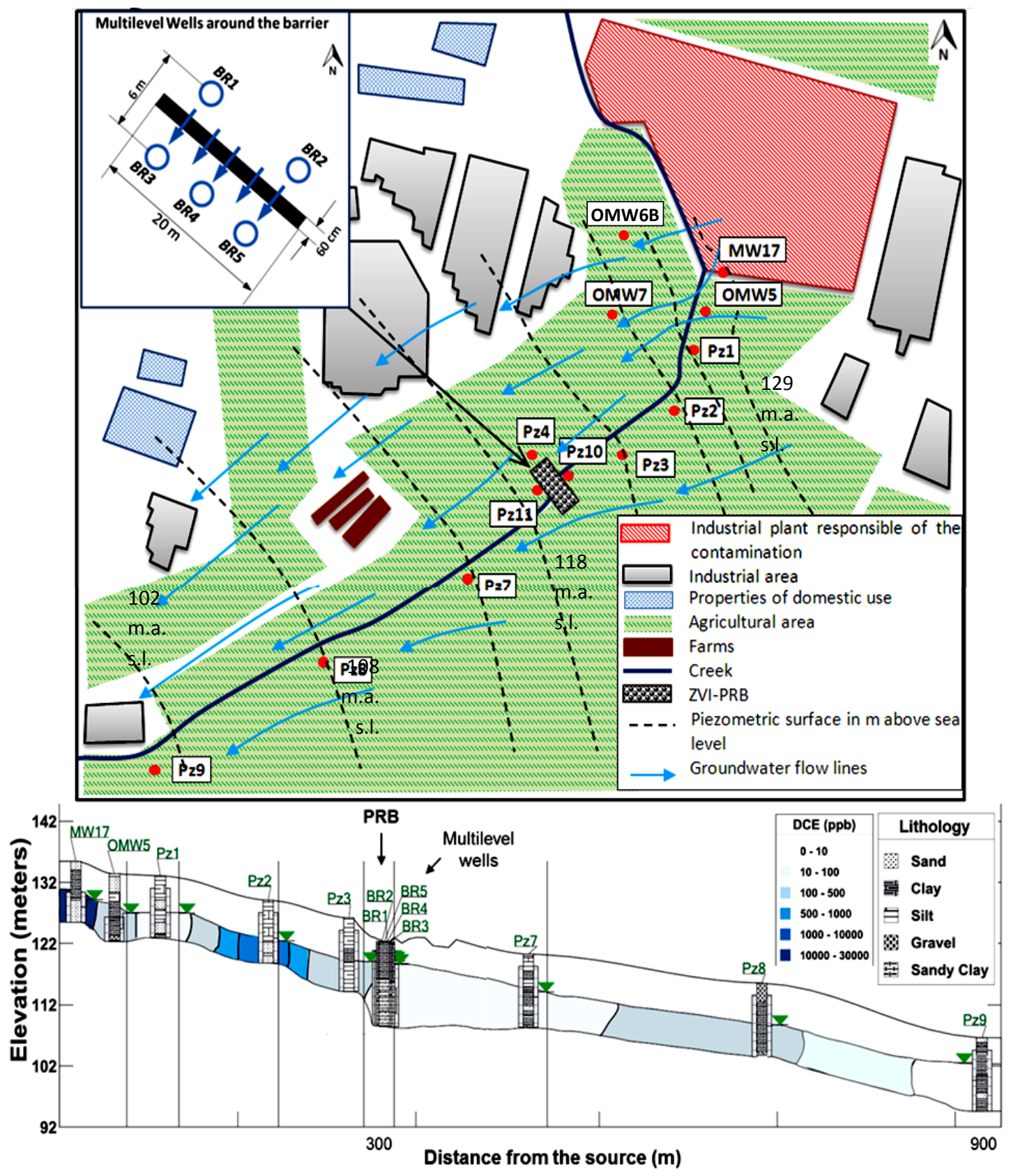

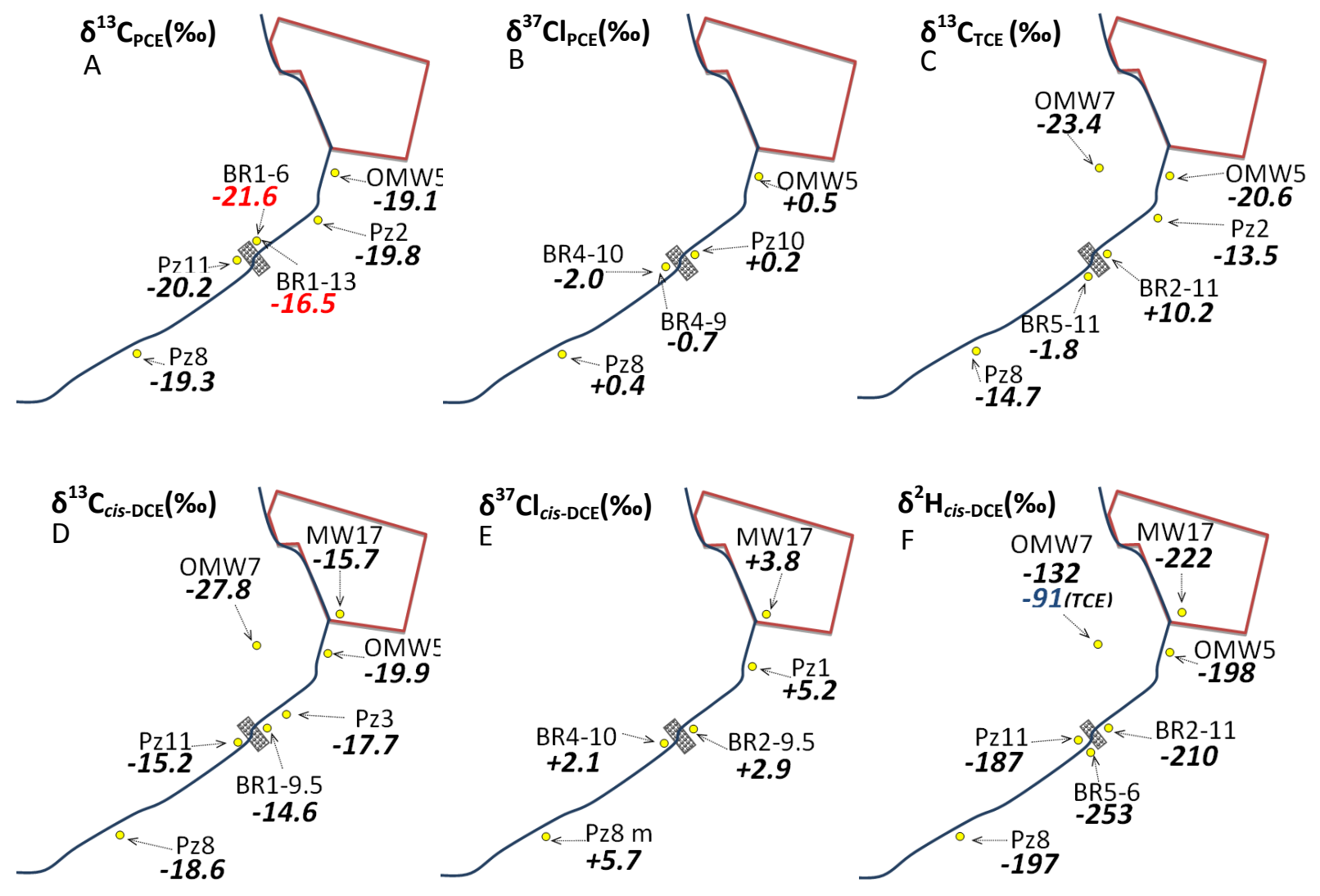


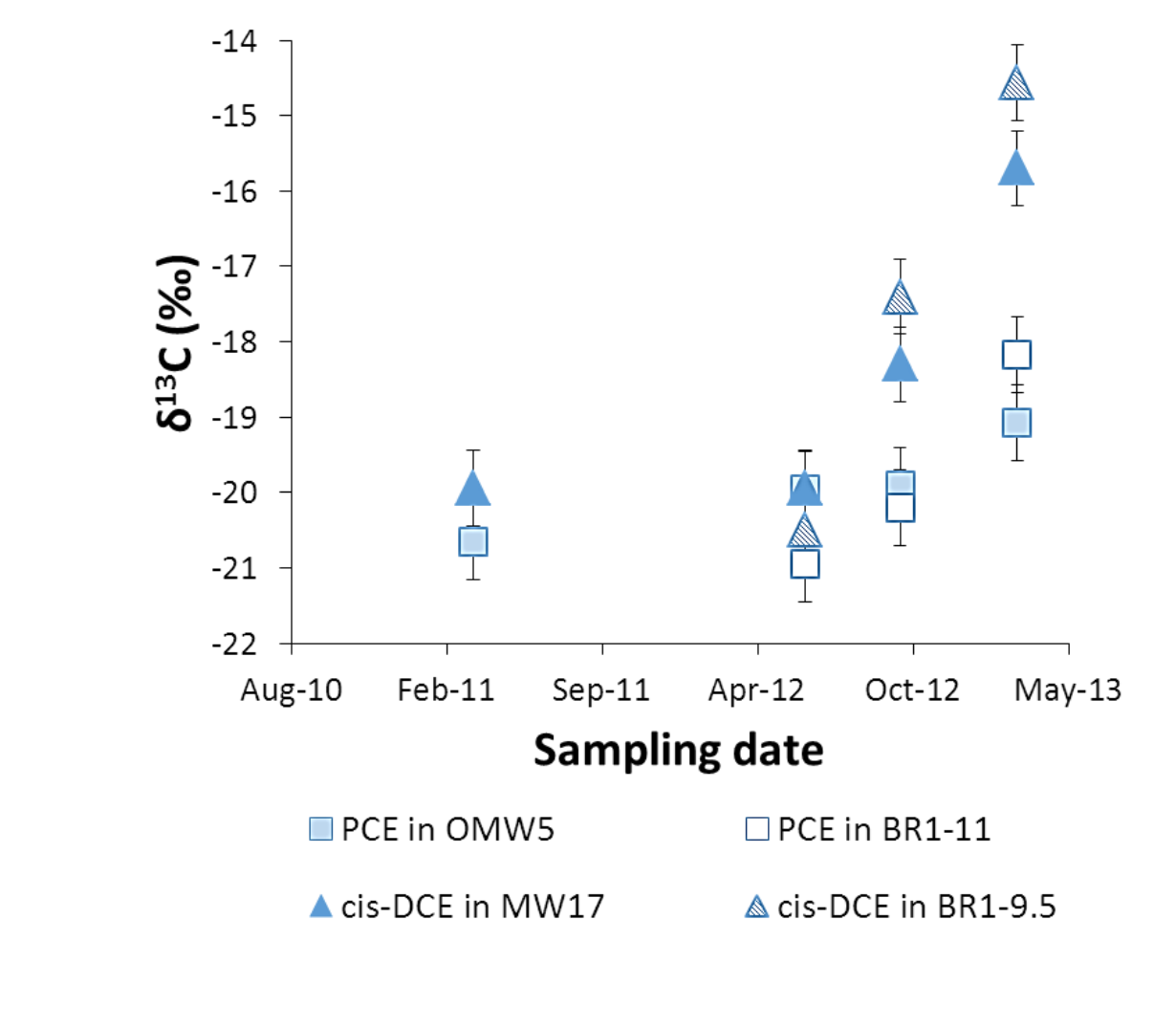

$\begin{array}{ll}\square \text { PCE in OMW5 } & \square \text { PCE in BR1-11 } \\ \triangle \text { cis-DCE in MW17 } & \triangle \text { cis-DCE in BR1-9.5 }\end{array}$

Figure 3

$\triangle$ cis-DCE in MW17 $\triangle$ cis-DCE in BR1-9.5

3

\section{Figure 3}

(1)

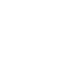

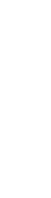

.

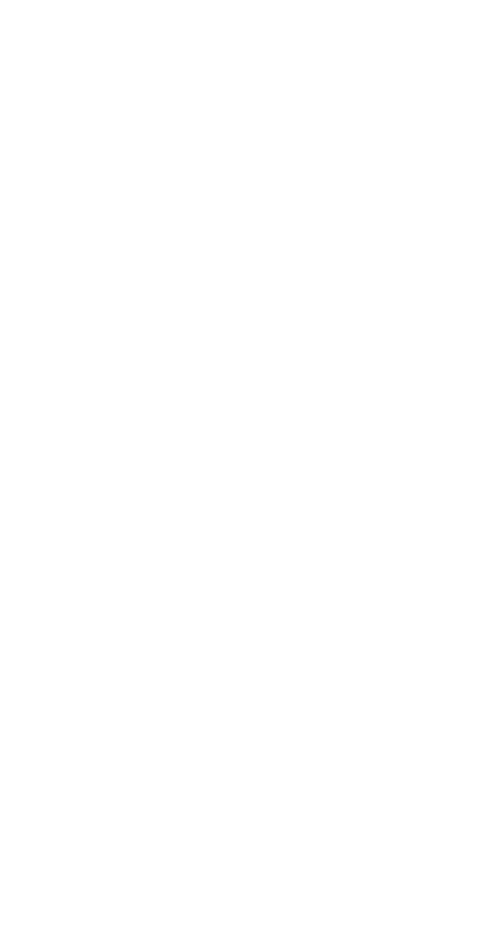



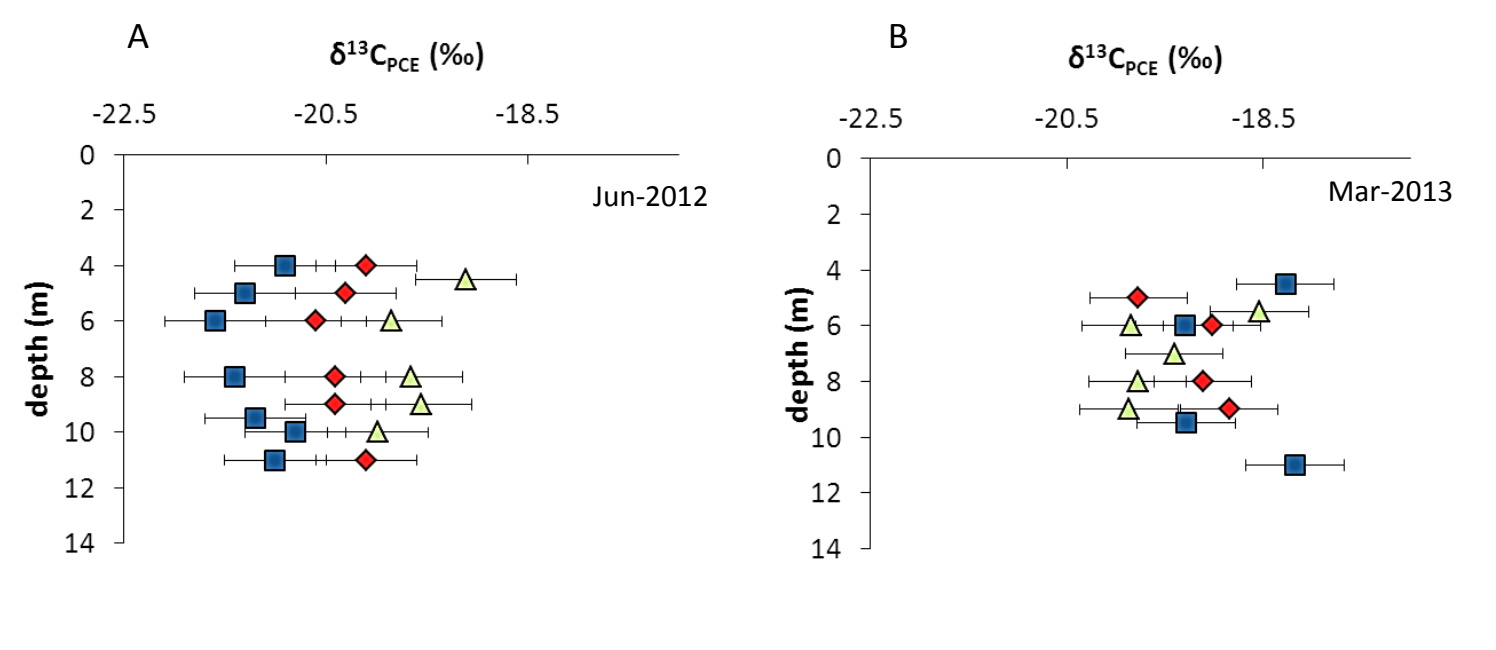

Figure 4

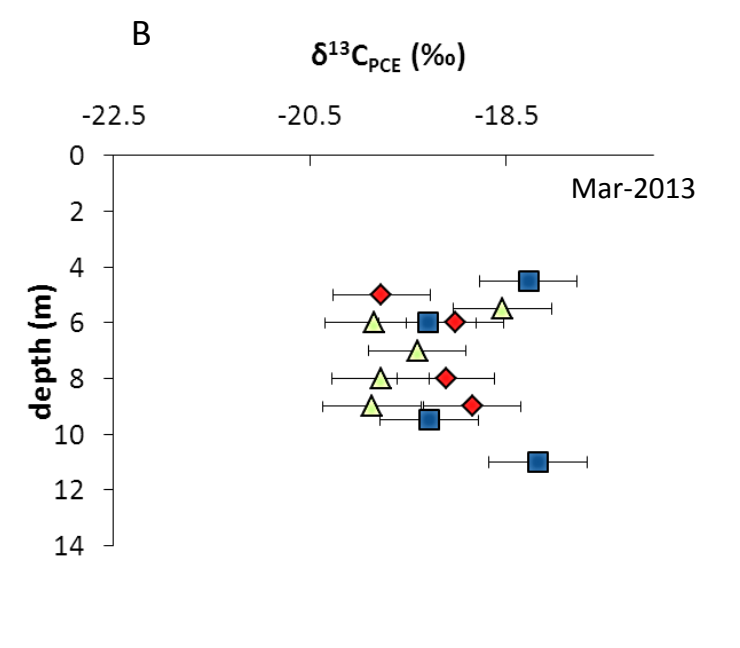

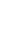

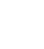

.

$+2$
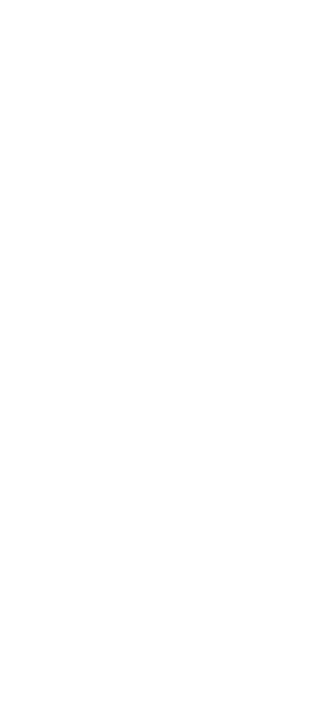
Figure 5

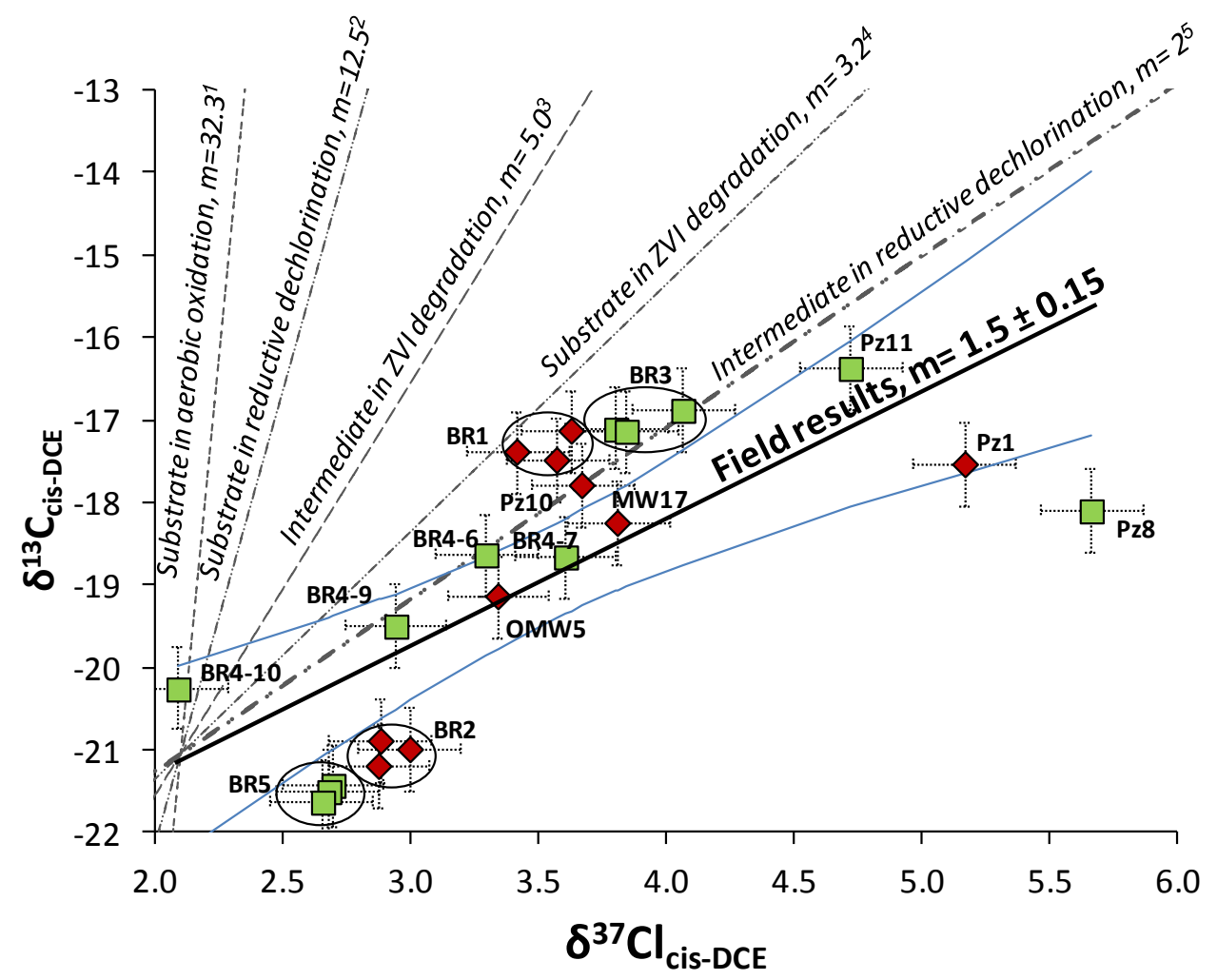

